\title{
Abiogenesis not required to explain the origin of volcanic- hydrothermal hydrocarbons
}

\author{
J. Fiebig ${ }^{1 *}$, A. Stefánsson ${ }^{2}$, A. Ricci ${ }^{3}$, F. Tassi ${ }^{4}$, F. Viveiros ${ }^{5}$, \\ C. Silva ${ }^{5,6}$, T.M. Lopez ${ }^{7}$, C. Schreiber ${ }^{1}$, S. Hofmann1 ${ }^{1}$, B.W. Mountain ${ }^{8}$
}

Abstract

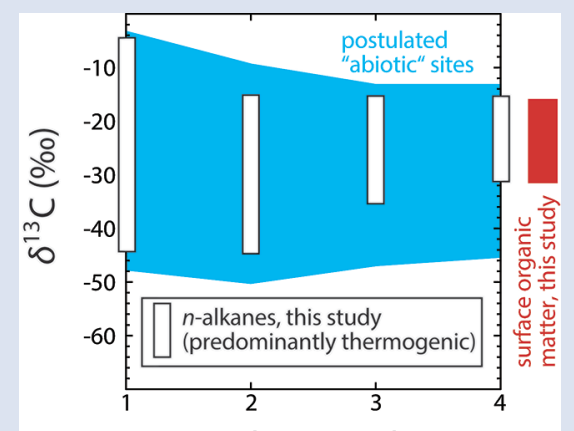

Carbon number

Abiotic formation of $n$-alkane hydrocarbons has been postulated to occur within Earth's crust. Apparent evidence was primarily based on uncommon carbon and hydrogen isotope distribution patterns that set methane and its higher chain homologues apart from biotic isotopic compositions associated with microbial production and closed system thermal degradation of organic matter. Here, we present the first global investigation of the carbon and hydrogen isotopic compositions of $n$-alkanes in volcanic-hydrothermal fluids hosted by basaltic, andesitic, trachytic and rhyolitic rocks. We show that the bulk isotopic compositions of these gases follow trends that are characteristic of high temperature, open system degradation of organic matter. In sediment-free systems, organic matter is supplied by surface waters (seawater, meteoric water) circulating through the reservoir rocks. Our data set strongly implies that thermal degradation of organic matter is able to satisfy isotopic criteria previously classified as being indicative of abiogenesis. Further considering the ubiquitous presence of surface waters in Earth's crust, abiotic hydrocarbon occurrences might have been significantly overestimated.

Received 11 April 2019 | Accepted 25 June 2019 | Published 29 July 2019

\section{Introduction}

The ability to distinguish between biotic and abiotic hydrocarbon sources on Earth is essential to understand fully the formation of crustal hydrocarbon reservoirs, identify the origin of hydrocarbons such as methane on other planets and resolve the potential role of abiotic methane in the emergence of life. It is well known that crustal hydrocarbons largely derive from biotic sources, i.e. from microbial production and thermal decomposition of organic matter (e.g., Etiope and Sherwood Lollar, 2013; Etiope and Schoell, 2014). Abiotic hydrocarbon formation (i.e. generation from pure inorganic substances, without any involvement of organic carbon) has been postulated to take place in a variety of natural systems where inorganically derived $\mathrm{CO}$ or $\mathrm{CO}_{2}$, water, reducing reagents and catalysts and/or heat are available. These include hydrothermal and low temperature $\left(\mathrm{T}<100^{\circ} \mathrm{C}\right)$ mafic and ultramafic systems, subduction-related, volcanic-hydrothermal systems and igneous intrusions (e.g., Etiope and Sherwood Lollar, 2013; Etiope and Schoell, 2014).
Most prominently, the following criteria have been used to identify abiotic hydrocarbon occurrences: i) methane with $\delta^{13} \mathrm{C} \geq-20 \%$ (e.g., Welhan and Craig, 1979), ii) the occurrence of a carbon isotope reversal between ethane and methane (i.e. methane more enriched in ${ }^{13} \mathrm{C}$ than ethane, contrary to what is observed for $n$-alkanes from confined sedimentary hydrocarbon reservoirs) (e.g., Des Marais et al., 1981; Sherwood Lollar et al., 2002; Proskurowski et al., 2008) and iii) methane in apparent chemical and isotopic equilibrium with inorganically derived $\mathrm{CO}_{2}$ (Fiebig et al., 2007). Using these criteria, contrary views have been presented on the origin of volcanic-hydrothermal $n$-alkanes. Whereas Des Marais et al. (1981) identified Yellowstone hydrocarbons to derive from a thermogenic source, Fiebig et al. (2007) ascribed n-alkanes from Nisyros, Vesuvio and Ischia to an abiotic origin. Recently, ${ }^{13} \mathrm{C}$-labelled experiments have called the relevance of abiotic hydrocarbon production under hydrothermal conditions into question, due to sluggish reaction rates (McCollom, 2016). Here, we present and discuss the first global data set of the carbon and hydrogen

\footnotetext{
Institute of Geosciences, Goethe University, Altenhöferallee 1, 60438 Frankfurt/Main, Germany

Institute of Earth Sciences, University of Iceland, Sturlugata 7, 101 Reykjavik, Iceland

Department of Biological, Geological and Environmental Sciences, University of Bologna, Piazza di Porta San Donato 1, 40126 Bologna, Italy

Department of Earth Sciences, University of Florence, Via La Pira 4, 50121 Florence, Italy

. Institute of Volcanology and Risks Assessment (IVAR), Universidade dos Açores, Rua da Mae de Deus, 9501-801 Ponta Delgada, Portugal

Centre for Information and Seismovolcanic Surveillance of the Azores, Rua da Mãe de Deus, 9501-801 Ponta Delgada, Portugal

Geophysical Institute, Alaska Volcano Observatory, University of Alaska Fairbanks, 903 Koyukuk Drive, Fairbanks, AK 99775, USA

GNS Science, Wairakei Research Centre, 114 Karetoto Road, Taupo 3384, New Zealand

Corresponding author (email: Jens.Fiebig@em.uni-frankfurt.de)
} 
isotope compositions of $n$-alkanes in hydrothermal fluids to gain more detailed insights into hydrocarbon formation under natural hydrothermal conditions.

\section{Methods}

We sampled two phase well fluids $(n=29)$ and steam vent fumaroles $(\mathrm{n}=61)$ from 28 volcanic-hydrothermal fields in New Zealand, Iceland, Argentina, USA (Alaska), Italy, Greece, Portugal (Azores) and Spain (Canary Islands) (Table S-1). Sampled locations represent all types of volcanism and a wide range of reservoir temperatures $\left(200-450{ }^{\circ} \mathrm{C}\right)$, with the origin of external water being dominantly meteoric and/or seawater (Table S-1 and references therein). Terrestrial vegetation at the sampled sites is largely dominated by $\mathrm{C}_{3}$ plants (Still et al., 2003). We analysed the carbon isotopic compositions of methane, ethane, propane and $n$-butane as well as the hydrogen isotopic compositions of methane and water in the discharged fluids (Supplementary Information; Tables S-2, S-3).

\section{Results and Discussion}

For several locations, carbon isotopes are homogeneously distributed among ethane, propane and $n$-butane $\left(\mathrm{C}_{2+}\right.$ hydrocarbons), with variations in $\delta^{13} \mathrm{C}_{2+} \leq 1.0 \%$ (Fig. 1a). At Reykjanes, $\delta^{13} \mathrm{C}-\mathrm{C}_{2+}$ of $-16 \%$ (well 11) and -17 to $-18 \%$ (well 12) overlap with the carbon isotopic composition of particulate organic carbon $\left(-17.5 \%\right.$ o $\geq \delta^{13} \mathrm{C}-\mathrm{POC} \geq-22.2 \%$ o) and modern sedimentary organic matter $\left(-16.5 \%\right.$ o $\geq \delta^{13} \mathrm{C}-\mathrm{SOM} \geq-19.4 \%$ o) that are characteristic of the water masses surrounding the Reykjanes peninsula (Sara et al., 2007). For Esguicho (Furnas village) $\delta^{13} \mathrm{C}-\mathrm{C}_{2+}$ of -28 to $-29 \%$ perfectly agree with the average carbon isotopic composition of terrestrial plants growing in the Furnas caldera (-28.4 \%o; Pasquier-Cardin et al., 1999). The hydrothermal reservoir at Reykjanes is predominantly fed by seawater, whereas the hydrothermal system beneath Furnas village is exclusively sourced by meteoric water (Table S-1). The same patterns - invariant $\delta^{13} \mathrm{C}-\mathrm{C}_{2+}$, but absolute values changing with the source of water - are observed at Nisyros (seawater-fed hydrothermal system, $\delta^{13} \mathrm{C}-\mathrm{C}_{2+}$ around $-18 \%$ ), Ischia and Rotokawa well 14 (both meteoric water-fed systems, $\delta^{13} \mathrm{C}-\mathrm{C}_{2+}$ around $-27 \%$ ) (Fig. 1a; Table S-1). These observations strongly imply that local organic matter is transported by external waters into the corresponding hydrothermal reservoirs, where it is finally subjected to high temperature pyrolysis. At these temperatures, the carbon isotope fractionation between the $\mathrm{C}_{2+}$ hydrocarbons and the source organic matter becomes insignificantly small and, hence, the $\delta^{13} \mathrm{C}-\mathrm{C}_{2+}$ becomes indicative of the bulk organic matter decomposing at depth.

Thermogenic $\mathrm{C}_{2+}$ hydrocarbon production is not restricted to systems with invariant $\delta^{13} \mathrm{C}-\mathrm{C}_{2+}$, but is most likely important in all systems. Although the majority of sampled discharges exhibit significant differences among $\delta^{13} \mathrm{C}-\mathrm{C}_{2+}$ values (Tables S-2, S-3), the carbon isotopic composition of $n$-butane, the longest $n$-alkane analysed in this study, consistently occurs within the range reported for modern marine dissolved organic carbon $\left(-18 \%\right.$ o $\geq \delta^{13} \mathrm{C}-\mathrm{DOC} \geq-23 \%$; Druffel et al., 1992), modern marine particulate organic carbon $\left(-17 \%\right.$ o $\geq \delta^{13} \mathrm{C}-\mathrm{POC} \geq-25 \%$; Druffel et al., 1992; Sara et al., 2007) and modern terrestrial $C_{3}$ plants $\left(-20 \%\right.$ o $\geq \delta^{13} \mathrm{C} \geq-37 \%$, with most data clustering between $-23 \%$ o $\geq \delta^{13} \mathrm{C} \geq-31.5 \%$ o and averaging at $\delta^{13} \mathrm{C}=-28.5 \%$; Kohn, 2010) (Fig. 1b). Moreover, relative variations in $\delta^{13} \mathrm{C}$ decrease in the order ethane propane $-n$-butane (Fig. 1b). Both patterns are consistent with isotope fractionation principles of organic matter degradation according to which the carbon isotope fractionation between
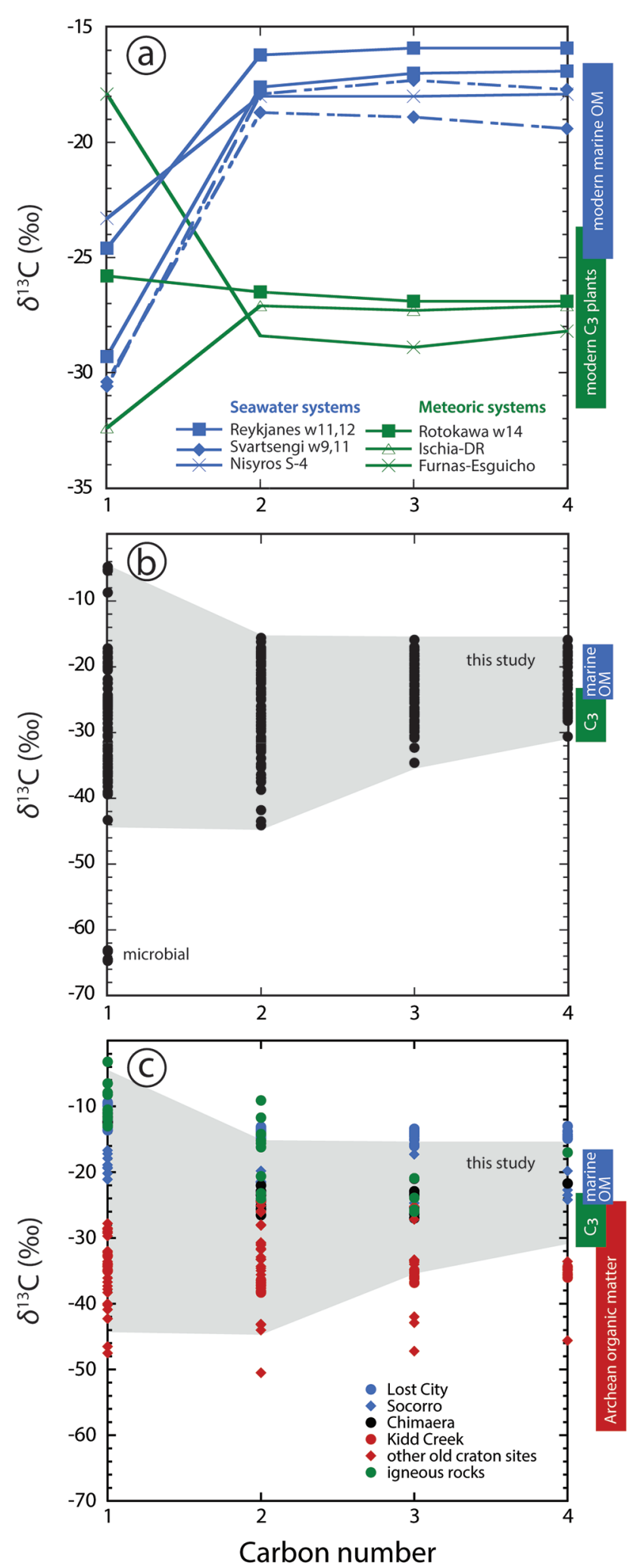

Figure 1 Plot of $\delta^{13} \mathrm{C}$ of individual $n$-alkanes against carbon number. $\delta^{13} \mathrm{C}$ ranges of modern marine organic matter (Druffel et al., 1992; Sara et al., 2007), terrestrial $C_{3}$ vegetation (Kohn, 2010) and Archean organic matter (Hayes and Waldbauer, 2006) are shown for comparison. (a) Emissions that are characterised by invariant $\delta^{13} \mathrm{C}_{-} \mathrm{C}_{2+\text {. }}$ (b) Compilation of all $n$-alkane data analysed in this study. (c) Comparison between $n$-alkane data from this study (area in grey) and data available from abiotic sites (Supplementary Information): hydrothermal sites (blue); ophiolite gases (black); old craton gases (red) and inclusions in igneous rocks (green). 

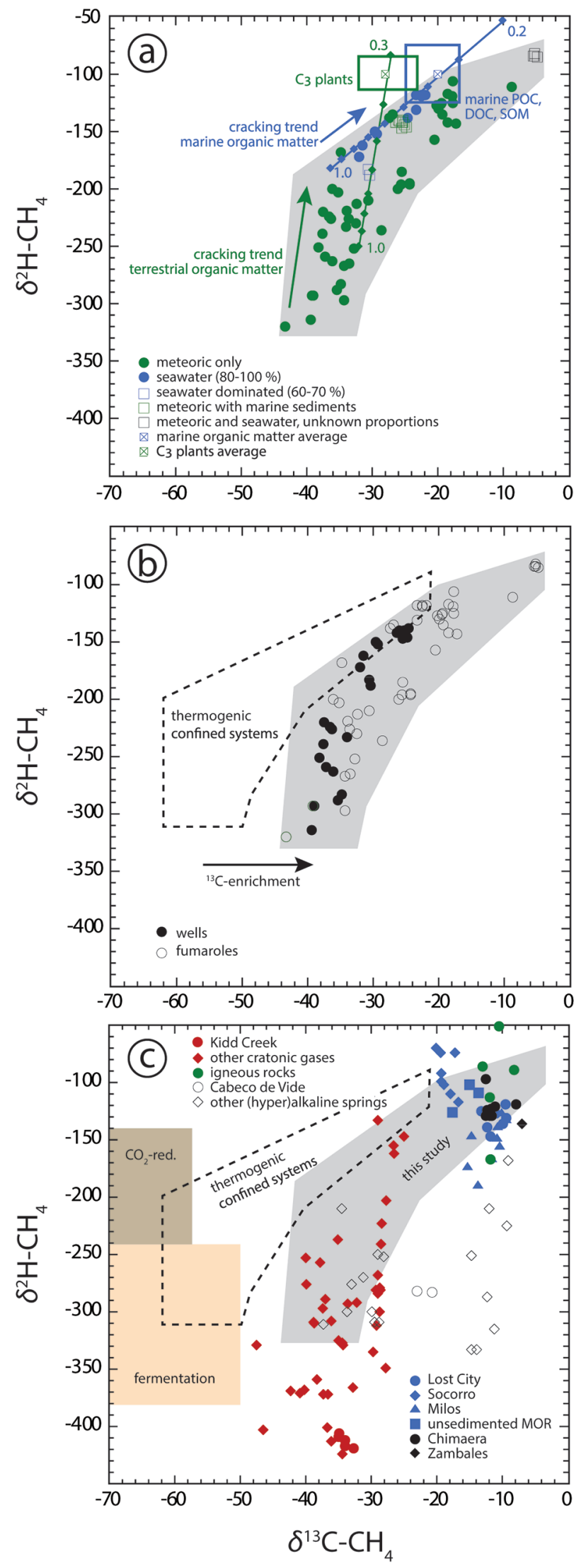

Figure 2 Plot of $\delta^{2} \mathrm{H}-\mathrm{CH}_{4}$ vs. $\delta^{13} \mathrm{C}_{-} \mathrm{CH}_{4}$. Samples with an obvious microbial origin $\left(8^{13} \mathrm{C}_{-} \mathrm{CH}_{4}<-60 \%\right.$, Fig. $\left.1 \mathrm{~b}\right)$ are not considered. (a) Data classified after the origin of external water feeding the hydrothermal system (Table S-1). Blue and green squares are representative of the carbon and hydrogen isotopic compositions of marine organic matter and $C_{3}$ plants, respectively (Schoell, 1984). The carbon and hydrogen isotopic compositions of instantaneously generated fractions of methane deriving from open system cracking of marine and terrestrial ( $C_{3}$ plants) organic matter were modelled as a function of the fraction of precursor sites remaining inside the cracked organic matter (Supplementary Information). The cracking trend for methane deriving from marine organic matter (blue line) matches the variation of $\delta^{13} \mathrm{C}^{-\mathrm{CH}_{4}}$ and $\delta^{2} \mathrm{H}-\mathrm{CH}_{4}$ observed for seawater-fed hydrothermal systems (blue data points). The cracking trend for methane from terrestrial organic matter (green line) corresponds to the slope described by most low $\delta^{13} \mathrm{C}_{-} \mathrm{CH}_{4}$ samples from meteoric water-fed hydrothermal systems (green data points), but - on average - occurs shifted relative to the latter to higher $\delta^{13} \mathrm{C}$ and $\delta^{2} \mathrm{H}$. This implies that methane precursor sites in decomposing terrestrial organic matter either occur depleted in ${ }^{13} \mathrm{C}$ and ${ }^{2} \mathrm{H}$ with respect to the average $C_{3}$ plant isotopic composition or that the corresponding carbon and hydrogen isotope fractionations $\left(\alpha_{C}, \alpha_{H}\right)$ are larger than those obtained from xylite (Berner et al., $1995)$, with $\alpha_{H} / \alpha_{C}$ remaining unchanged. Both possibilities are consistent with carbon isotope constraints on pyrolysis of coal (Cramer et al., 1998). (b) Data classified after the style of degassing (wells vs. fumaroles). (c) Comparison between methane data from this study and data available from other abiotic sites (Supplementary Information): labelling as in Figure 1c, extended by (hyper)alkaline spring data (open symbols). Field characteristic for methane from microbial (c) and confined sedimentary systems (b, c) redrawn after Schoell (1988).

source organic matter and the evolving gaseous $n$-alkane decreases with the number of carbon atoms constituting the $n$-alkane (Tang et al., 2000). In addition to the modern organic matter supplied by external waters, older organic matter contained in sediments can also contribute to overall hydrocarbon production, as becomes evident from Rotokawa $\delta^{13} \mathrm{C}$ $\mathrm{C}_{2+}$ data (Table S-2). Although the Rotokawa hydrothermal reservoir is exclusively sourced by meteoric waters (Table S-1), its $\delta^{13} \mathrm{C}-n-\mathrm{C}_{4}$ values range from -27 to $-17 \%$, pointing to the occurrence of a marine next to a terrestrial organic source. The marine organic end member is likely hosted in Mesozoic greywacke located at relatively shallow depths of 1-3 km underneath Rotokawa (Table S-1 and references therein).

Several additional observations imply that methane in the sampled discharges is also predominantly derived from the thermal decomposition of organic matter, and that the source organics are transported by external waters from the surface to reservoir depth. First, even if methane samples with an obvious microbial origin (Furnas B and Furnas Lake 2, Azores; Table S-3), as indicated by relatively strong depletions in ${ }^{13} \mathrm{C}$ and ${ }^{2} \mathrm{H}$; Whiticar et al., 1999) are excluded, methane still exhibits the largest variations in $\delta^{13} \mathrm{C}$ of all analysed $n$-alkanes (Fig. 1b). Second, in $\delta^{13} \mathrm{C}$ vs. $\delta^{2} \mathrm{H}$ space (Fig. 2a), methane from meteoric water- and seawater-fed hydrothermal systems plots along trends that are characteristic of open system, high temperature cracking of terrestrial and marine organic matter, respectively (Berner et al., 1995; Supplementary Information). Third, in the same space, methane from volcanic-hydrothermal systems plots into a field that has a shape similar to that characteristic of thermogenic methane from confined sedimentary systems but is, relative to the latter, shifted to higher $\delta^{13} \mathrm{C}$ values (Fig. 2b). Generally, the magnitude of carbon isotope fractionation between precursor organic matter and evolving $n$-alkane decreases with increasing temperature (e.g., Tang et al., 2000). The observed ${ }^{13} \mathrm{C}$-enrichment of thermogenic methane in volcanic-hydrothermal fluids may, therefore, result from relatively high reservoir temperatures of $200-450{ }^{\circ} \mathrm{C}$ (Table S-1), well-exceeding those of confined sedimentary reservoirs where methane generation takes place primarily between $150-220{ }^{\circ} \mathrm{C}$ (Quigley and MacKenzie, 1988). In addition, modern marine organic matter is enriched in ${ }^{13} \mathrm{C}$ by 5 to $10 \%$ relative to the marine organic matter of pre-Cenozoic age (Hayes et al., 1999) that provides the source of kerogen in confined sedimentary reservoirs. Fourth, in Icelandic systems, which are characterised by the absence of 
organic sediments, DOC and POC concentrations of meteoric water and/or seawater alone are sufficiently high to balance $n$-alkane concentrations in the discharged fluids (Fig. S-1). Fifth, under steady state conditions, water recharge rates at depth should be higher in well reservoirs than in naturally degassing systems, as in well systems the reservoir fluid is continuously exploited at the surface in addition to the steam. The flux of fresh, immature organics (depleted in ${ }^{13} \mathrm{C}$ ) through the reservoir should, therefore, be higher in well systems. This is consistent with the observation that well discharges display on average lower $\delta^{13} \mathrm{C}-\mathrm{CH}_{4}$ values than fumaroles (Fig. 2b).

Two reasons may account for $\delta^{2} \mathrm{H}$ departing from the predicted cracking and degassing trends at high organic matter maturities characterised by $\delta^{13} \mathrm{C}-\mathrm{CH}_{4} \geq-20 \%$ (Fig. 2a). First, hydrogen isotope exchange between $\mathrm{CH}_{4}$ and water may occur at the elevated temperatures characteristic of hydrothermal systems, driving $\mathrm{CH}_{4}$ towards isotopic equilibrium with water at $\mathrm{T} \geq 300^{\circ} \mathrm{C}$ (Fig. S-2a). Alternatively, the decomposing organic matter at depth may be able to exchange hydrogen with the reservoir water such that the hydrogen isotopic composition of the organic matter and that of the methane becomes progressively buffered by water with increasing temperature and/or increasing organic matter maturity.

The isotopic signature of $n$-alkanes from potential abiotic natural sites and our samples are shown for comparison in Figs. 1c and 2c. There is significant overlap between our data and the inferred abiotic data set. However, based on our observations we consider a predominantly abiotic origin for the volcanic-hydrothermal hydrocarbons to be highly unlikely. In particular, a predominantly abiotic origin of the $n$-alkanes analysed in this study would require that our overall data set fortuitously follows isotopic fractionation principles that are characteristic of thermogenesis as detailed above.

Our observation that the overall isotopic trends displayed by volcanic-hydrothermal hydrocarbons are consistent with a predominant thermogenic origin for these gases has important implications for the reliability of criteria previously applied to identify abiotic hydrocarbon occurrences. First, $\delta^{13} \mathrm{C}-\mathrm{CH}_{4}$ values exceeding those characteristic for methane from confined sedimentary systems are not indicative of abiogenesis (Fig. 2a). Second, the occurrence of a carbon isotope reversal (as is observed for several locations in this study; see Tables S-2, S-3) cannot be used as evidence for abiotic $n$-alkane generation either. Reversals can be obtained from thermogenic degradation and open system degassing alone (Fig. S-3), or from mixing of thermogenic $n$-alkanes from two or more sources of distinct organic maturity (Taran et al., 2007). Third, because $\delta^{13} \mathrm{C}_{-} \mathrm{CH}_{4}$ is controlled by the relative fluxes of organic carbon into and methane carbon out of the system, carbon isotope equilibrium between $\mathrm{CH}_{4}$ and $\mathrm{CO}_{2}$ might not be attained, such that the apparent fractionation would only fortuitously correspond to equilibrium in some cases (Figs. S-2b, S-4).

\section{Conclusions}

$\delta^{2} \mathrm{H}$ and $\delta^{13} \mathrm{C}$ of $\mathrm{CH}_{4}$ as well as $\delta^{13} \mathrm{C}$ of $\mathrm{C}_{2+}$ of $n$-alkanes from volcanic-hydrothermal emissions follow isotopic trends that are consistent with the principles of organic matter degradation under relatively high temperatures and open system conditions. No significant contribution from an abiotic source is required to explain the isotopic compositions and trends displayed by these $n$-alkanes. Source organic matter is supplied by external, surface-derived waters circulating through these systems and, if present, by sedimentary host rocks. Previously applied criteria characteristic for thermogenic hydrocarbon classification were developed for confined sedimentary thermogenic systems such as oil and gas fields that were not open to degassing during organic matter maturation. We argue that these criteria are not applicable to thermogenic systems open to degassing. Under such open system conditions, unusual enrichment in ${ }^{13} \mathrm{C}$ and even carbon isotope reversals between methane and ethane can be obtained. As a consequence, reported abiotic hydrocarbon occurrences may be significantly overestimated, by mistakenly ascribing thermogenic hydrocarbons to an abiotic origin.

\section{Acknowledgements}

This work became possible through DFG grant FI 948/8-1.

Editor: Liane G. Benning

\section{Additional Information}

Supplementary Information accompanies this letter at http:// www.geochemicalperspectivesletters.org/article1920.

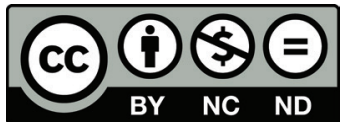

This work is distributed under the Creative Commons Attribution Non-Commercial No-Derivatives 4.0 License, which permits unrestricted distribution provided the original author and source are credited. The material may not be adapted (remixed, transformed or built upon) or used for commercial purposes without written permission from the author. Additional information is available at http://www.geochemicalperspectivesletters.org/ copyright-and-permissions.

Cite this letter as: Fiebig, J., Stefánsson, A., Ricci, A., Tassi, F., Viveiros, F., Silva, C., Lopez, T.M., Schreiber, C., Hofmann, S., Mountain, B.W. (2019) Abiogenesis not required to explain the origin of volcanic-hydrothermal hydrocarbons. Geochem. Persp. Let. 11, 23-27.

\section{References}

Berner, U., Faber, E., Scheeder, G., Panten, D. (1995) Primary cracking of algal and landplant kerogens: kinetic models of isotope variations in methane, ethane and propane. Chemical Geology 126, 233-245.

Cramer, B., Krooss, B.M., LitTKe, R. (1998) Modelling isotope fractionation during primary cracking of natural gas: a reaction kinetic approach. Chemical Geology 149, 235-250.

Des Marais, D.J., Donchin, J.H., Nehring, N.L., Truesdell, A.H. (1981) Molecular carbon isotopic evidence for the origin of geothermal hydrocarbons. Nature 292, 826-828.

Druffel, E.R.M., Williams, P.M., BAuer, J.E., Ertel, J.R. (1992) Cycling of dissolved and particulate organic matter in the open ocean. Journal of Geophysical Research 97, 15639-15659.

Etiope, G., SHerwood Lollar, B. (2013) Abiotic methane on Earth. Reviews of Geophysics 51, 276-299

Etiope, G., Schoell, M. (2014) Abiotic gas: atypical but not rare. Elements 10, 291-296.

Fiebig, J., Woodland, A.B., Spangenberg, J., Oschmann, W. (2007) Natural evidence for rapid abiotic hydrothermal generation of $\mathrm{CH}_{4}$. Geochimica et Cosmochimica Acta 71, 3028-3039.

Hayes, J.M., Strauss, H., KaUfmanN, A.J. (1999) The abundance of ${ }^{13} \mathrm{C}$ in marine organic matter and isotopic fractionation in the global biogeochemical cycle of carbon during the past $800 \mathrm{Ma}$. Chemical Geology $161,103-125$.

HAYES, J.M., WALDBAUER, J.R. (2006) The carbon cycle and associated redox processes through time. Philosophical Transactions of the Royal Society B 361, 931-950.

KoHN, M.J. (2010) Carbon isotope compositions of terrestrial $C_{3}$ plants as indicators of (paleo)ecology and (paleo)climate. Proceedings of the National Academy of Sciences of the USA 107, 19691-19695 
MCCollom, T.M. (2016) Abiotic methane formation during experimental serpentinization of olivine. Proceedings of the National Academy of Sciences of the USA 113, 13965-13970.

Pasquier-Cardin, A., Allard, P., Ferreira, T., Hatte, C., Coutinho, R., Fontugne, M., Jaudon, M. (1999) Magma-derived $\mathrm{CO}_{2}$ emissions recorded in ${ }^{14} \mathrm{C}$ and ${ }^{13} \mathrm{C}$ content of plants growing in Furnas caldera, Azores. Journal of Volcanology and Geothermal Research 92, 195-207.

Proskurowski, G., Lilley, M.D., Seewald, J.S., Früh-Green, G.L., Olson, E.J., LuPton, J.E., SYlva, S.P., Kelley, D.S. (2008) Abiotic hydrocarbon production at Lost City hydrothermal field. Science 319, 604-607.

Quigley, T.M., MacKenZIE, A.S. (1988) The temperatures of oil and gas formation in the sub-surface. Nature 333, 549-552.

Sara, G., De Pirro, M., Romano, C., Rumolo, P., Sprovieri, M., MazzolA, A. (2007) Sources of organic matter for intertidal consumers on Ascophyllum-shores (SW Iceland): a multi-stable isotope approach. Helgoland Marine Research 61, 297-302.

ScHOELL, M. (1984) Wasserstoff- und Kohlenstoffisotope in organischen Substanzen, Erdölen und Erdgasen. Geologisches Jahrbuch D67, 1-161.

SchoELl, M. (1988) Multiple origins of methane in the Earth. Chemical Geology 71, 1-10.

Sherwood lollar, B., Westgate, T.D., Ward, J.A., Slater, G.F., LACRAMPE-Couloume, G. (2002) Abiotic formation of gaseous alkanes in the Earth's crust as a minor source of global hydrocarbon reservoirs. Nature 416, 522-524

Still, C.J., Berry, J.A., Collatz, G.J., DeFries, R.S. (2003) Global distribution of $C_{3}$ and $C_{4}$ vegetation: Carbon cycle implications. Global Biogeochemical Cycles 17, doi: 10.1029/2001GB001807.

TAnG, Y., Perry, J.K., Jenden, P.D., Schoell, M. (2000) Mathematical modeling of stable carbon isotope ratios in natural gases. Geochimica et Cosmochimica Acta 64, 2673-2687.

Taran, Y.A., Kliger, G.A., Sevastyanov, V.S. (2007) Carbon isotope effects in the open-system Fischer-Tropsch synthesis. Geochimica et Cosmochimica Acta 71, 4474-4487.

Welhan, J.A., Craig, H. (1979) Methane and hydrogen in East Pacific Rise hydrothermal fluids. Geophysical Research Letters 6, 829-831.

WHITICAR, M.J. (1999) Carbon and hydrogen isotope systematics of bacterial formation and oxidation of methane. Chemical Geology 161, 291-314. 